\title{
La arquitectura como acontecimiento a través del Black Mountain College.
}

\author{
Gilsanz Díaz, Ana.
}

Arquitecta. Doctorando del Departamento de Expresión Gráfica y Cartografía, Área de Composición Arquitectónica, Universidad de Alicante, España. acgd@alu.ua.es

\section{Resumen}

Black Mountain College fue una institución educativa norteamericana que funcionó como centro de creación multidisciplinar y residencia artística, donde la experimentación desde las distintas áreas de conocimiento era esencial en el proceso formativo. La arquitectura estaba presente en su proyecto docente a través de profesionales que impartieron clase o lo visitaron y, de propuestas y acciones que demuestran la capacidad de la arquitectura de entenderse como acontecimiento.

El presente artículo se centra en el Black Mountain College, realizando una aproximación a su arquitectura, entendiendo ésta como una actividad multidisciplinar propositiva y estudiándola a través de los acontecimientos que tuvieron lugar en el centro y su presencia en el proyecto educativo. Unas ideas y modos de trabajo desarrolladas bajo una filosofía global que se encuentran vigentes en la actualidad, por más que hayan pasado casi ochenta años desde su fundación.

Por último, se identifican los vínculos que se establecieron entre esta institución y España a través de las figuras que formaron parte de esta experiencia.

Palabras clave: Black Mountain College, acontecimiento, interdisciplinariedad, experimentación, colaboración.

\begin{abstract}
Black Mountain College was an American educational institution that worked as a multidisciplinary center and artistic residence, where experimentation was essential in the learning process. The architecture was present in his teaching project, through professionals who taught or visited the College and proposals and actions that demonstrate the ability of architecture to be understood as an event.

This article focuses on the Black Mountain College, making an approach to its architecture, understood as a proactive multidisciplinary activity and studying it through the events that took place there and its presence in the educational project. Ideas and ways of working developed under a global philosophy which are in force at present, though nearly eighty years have passed since its founding.
\end{abstract}

Finally, the links established between this institution and Spain, through the figures that were part of this experience, are identified.

Key words: Black Mountain College, event, interdisciplinarity, experimentation, collaboration. 
Innovación e Investigación en Arquitectura y Territorio. Departamento de Expresión Gráfica y Cartografía. Arquitectura. Escuela Politécnica Superior. Universidad de Alicante. N³ septiembre 2015 ISSN: 2341-0515

\section{Introducción: La arquitectura como acontecimiento y el Black Mountain College.}

Este artículo tiene su origen en entender la arquitectura desde la interdisciplinariedad, abarcando distintos modos de expresión en un continuo proceso de aprendizaje y en relación directa con la experimentación y con la realidad.

La arquitectura como acontecimiento, entendida como actividad multidisciplinar donde se producen una serie de acciones e interacciones generadoras de efectos. Se puede pensar la arquitectura como un sistema de acontecimientos en los que espacio y tiempo están simultáneamente presentes como categorías abiertas, múltiples y organizadoras. Un sistema complejo de realidades diversas y abiertas que se entrecruzan, yuxtaponen y superponen generando acontecimientos, en ocasiones con cierto carácter imprevisible y relevante.

El acercamiento se realiza a través de lo sucedido en el Black Mountain College (en adelante B.M.C). Institución educativa norteamericana que existió entre 1933 y 1957 en Black Mountain, Carolina del Norte y que fue un centro de producción, creación y experimentación multidisciplinar, donde coincidieron distintos profesionales que mediante sus programas y actividades dieron lugar a acontecimientos donde la arquitectura estaba presente de diversas maneras, en mayor o menor grado, siempre en un contexto interdisciplinar.

Lo acontecido allí, muestra uno de los ejemplos y modelos de creación colectiva donde la participación y colaboración de estudiantes y profesores resulta fundamental. Un lugar de confluencia de diversos intereses y disciplinas, desde una situación intelectual, heurística y vital. Enfocado desde la mirada de otras disciplinas transversales además de la propia arquitectura, tales como la ciencia y las artes en general y dentro del contexto espacio temporal de la inestabilidad donde se desarrolló, que surge como resultado de los fuertes procesos de transformación de las estructuras económicas, políticas, sociales y culturales.

B.M.C se funda con el objetivo de dar una educación para la vida, sin distinción entre profesores y alumnos, ni entre los facultativos y los órganos de administración. Marca un hito en la trayectoria formativa en las disciplinas artísticas y arquitectónicas en EE.UU. Convirtiéndose en un espacio pionero y germen de la cultura norteamericana enraizada con los diversos profesionales, profesores permanentes y visitantes que pasaron a lo largo de los 24 años de existencia de la institución.

Todo esto sucede en un contexto espacio temporal concreto, el de la Segunda Guerra Mundial, donde se produce el traslado artístico-intelectual de Europa a EE.UU., pero también el político y económico, a través de algunas de las figuras de la Bauhaus que tras la llegada de Hitler al poder en Alemania se desplazan principalmente a Harvard, Illinois Institute of Technology, Massachusetts Institute of Technology y al B.M.C.

El B.M.C ha sido estudiado principalmente desde el punto de vista pedagógico, como paradigma educativo de la formación progresista y artística por los distintos profesionales relacionados con las artes que fueron docentes allí, así como por la repercusión de algunos de los que fueron alumnos ${ }^{2}$. Fue un centro de estudios y residencia artística y es considerado un laboratorio de medios y formas de expresión, innovación educativa y artística. Una utopía educativa basada en la comunidad participativa, que se consolidó como lugar de encuentro clave de artistas, pensadores, profesores y científicos ${ }^{3}$.

\section{Objetivos y metodología.}

La investigación se centra en el concepto de acontecimiento enfocado en el B.M.C y pretende recomponer o reconstruir las bases de la misma, en función del material disponible y mediante un acercamiento que aborda tres áreas:

La exploración, recopilación y revisión del acontecimiento desde el punto de vista de la disciplina de la arquitectura en relación con el resto de artes y actividades que se desarrollaron en el B.M.C.

\footnotetext{
1 Cabe destacar Walter Gropius y Marcel Breuer en Harvard. Mies Van der Rohe en Illinois Institute of Technology. Laszlo Moholy Nagy en New Bauhaus. Josef y Anni Albers en Black Mountain College y Yale.

${ }^{2}$ A pesar de que al final de sus existencia el número de graduados no fue muy elevado, aproximadamente 60, pasaron gran número de alumnos, alrededor de unos 1200 a lo largo de la existencia de la institución, entre los que destacan entre otros Ruth Asawa, Ray Johnson, Elaine de Kooning, Louise Lippold, Keneth Noland, Joel Oppenheimer, Francine du Plessix, Arthur Penn, Robert Rauschenberg, Dorothea Rockburne, Michael Rumaker, Cy Twombly, Kenneth Snelson, Susan Weil y Vera Williams.

${ }^{3}$ Algunos de los profesionales que se acercaron o que coincidieron como profesores en el Black Mountain College fueron Josef Albers, Anni Albers, Eric Bentley, Alfred Kazin, John Cage, Harry Callahan, Robert Creeley, Merce Cunningham, Max Dehn, Robert Duncan, Alfred Einstein, Willem de Kooning, Buckminster Fuller, Walter Gropius, Lou Harrison, Franz Kline, Jacob Lawrence, Richard Lippold, Katherine Litz, Robert Motherwell, Charles Olson, David Tudor, Ben Shahn, Aaron Siskind, Theodoros Stamos y Jack Tworkov, entre otros.
} 
El análisis de la presencia de la arquitectura y los arquitectos en la institución.

La aproximación e identificación de los vínculos con España a través de las figuras involucradas en el B.M.C.

Este trabajo pretende ser un acercamiento, una recuperación de lo sucedido en el B.M.C a nuestro idioma, puesto que la gran parte de información relativa a esta institución se encuentra editada en inglés. Pretende revisitar y poner en valor los acontecimientos que tuvieron lugar allí, entender la arquitectura y los fenómenos socioculturales y productivos hibridados con ella.

El interés radica en su vigencia actual como modo de reinvención, oportunidad y necesidad en los planteamientos y maneras de afrontar la profesión. Además del enriquecimiento de la arquitectura del resto de las disciplinas mediante una visión global. Una arquitectura abierta al suceso y a una mirada transversal.

Se realiza una investigación analítica de recopilación, selección y síntesis de datos relacionados con el B.M.C. Una recopilación a través de las diversas fuentes: libros, documentos escritos y audiovisuales de los distintos archivos y bibliotecas, revisión de investigaciones anteriores específicas sobre la materia o que estén vinculadas de manera tangencial. Una selección que incluye la organización y análisis de la información recopilada. Una síntesis de los datos, mediante la elaboración de fichas que clasifican y valoran la información y la realización de diversos diagramas explicativos de las distintas conexiones y acontecimientos. Un método de trabajo que permite reseñar tanto los datos como las características más importantes de cada acontecimiento seleccionado, su valoración y su significación. El material analizado y sintetizado en las fichas clasificatorias, es transformado en unos diagramas, a modo de información gráfica, que facilita la lectura y el análisis de la información recopilada.

\section{El acontecimiento en el Black Mountain College.}

Harold Rosenberg acuñó el término Action Painting ${ }^{4}$ donde pone de manifiesto la importancia de la acción en el lienzo como propia representación. El arte como acción que descansa sobre el supuesto de que el artista acepta como real lo que ocurre durante su proceso creativo, poniendo énfasis en la experiencia o experimentación de los nuevos action painters. De manera que lo que sucede en un lienzo no es una imagen sino un acontecimiento.

Al margen de una clasificación desde el ámbito del arte, el acontecimiento es el resultado de la acción:

"A su vez el acontecimiento es también un punto de encuentro, una conjunción en la que líneas de recorrido ilimitado se entrecruzan con otras creando puntos nodales de una intensidad emergente. Finalmente el acontecimiento es una aprehensión, el resultado de la acción de un sujeto que en fluir caótico de los acontecimientos atrapa los que más le atraen o más le conmueven para retenerlos. Es una acción subjetiva. Produce un momento de gozo y de una frágil plenitud". ${ }^{5}$

Estas definiciones se aproximan a los acontecimientos sucedidos en el B.M.C que demuestran la capacidad de la arquitectura de ser acontecimiento, de existir sin una finalidad y duración concreta. Un interés que reside en el qué y cómo se hace, en el proceso más que en un resultado material concreto.

\subsection{Metodología educativa.}

Para entender el B.M.C y todo lo que sucedió allí adquieren relevancia los métodos de enseñanza sobre los que se fundamenta:

La comunidad, entendiendo la vida, el trabajo y el estudio dentro del B.M.C. Una organización fundamentada en la libertad y la responsabilidad individual, en un entorno de colaboración entre los componentes del College. Libertad creativa, de enseñanza y de elección, también para los estudiantes, de la que cada uno a nivel individual es responsable y aprende de ella.

La democracia. Una estructura organizativa democrática, no jerarquizada y participativa, que se reúne en asambleas donde existe un consejo formado por un rector, ocho profesores y con la presencia de un alumno elegido por sus propios compañeros. Un lugar donde todos tienen voz y voto y, donde los profesores y estudiantes cambian de roles frecuentemente en función de lo que puedan aportar a la comunidad.

La interdisciplinariedad basada en la colaboración como constante en sus planteamientos y actividades, donde el arte es el centro de la educación. La interdisciplinariedad produce una pluralidad de fuentes de información y

\footnotetext{
${ }^{4}$ ROSENBERG, Harold. "The American Action Painters". Art News 51/8 New York (1952) p.22.

${ }^{5}$ DE SOLÁ MORALES, Ignasi. Diferencias: Topografía de la arquitectura contemporánea. Barcelona: Ed. Gustavo Gili (2003) p. 112.
} 
datos que posibilitan el aprendizaje y el descubrimiento, a través de la multiplicidad de experiencias, integrando la actividad artística con la experiencia real.

La acción como manera de posicionarse, resultado de la observación y la experimentación. La experimentación es una idea recurrente en los discursos relativos a esta institución en el ámbito educativo, la vida en comunidad y en el arte.

“Experimentar, es en principio, más importante que producir; en los inicios, la libre experimentación contribuye a desarrollar el coraje"

El objetivo de Josef Albers era "Abrir los ojos"”. Si un profesor consigue que un alumno perciba con más claridad le habrá otorgado una ventaja artística, enfatizando la necesidad de entrenar la percepción a través de la observación. Posicionamientos que fomentaban la interacción con el alumno y aprender mediante los sentidos y la acción.

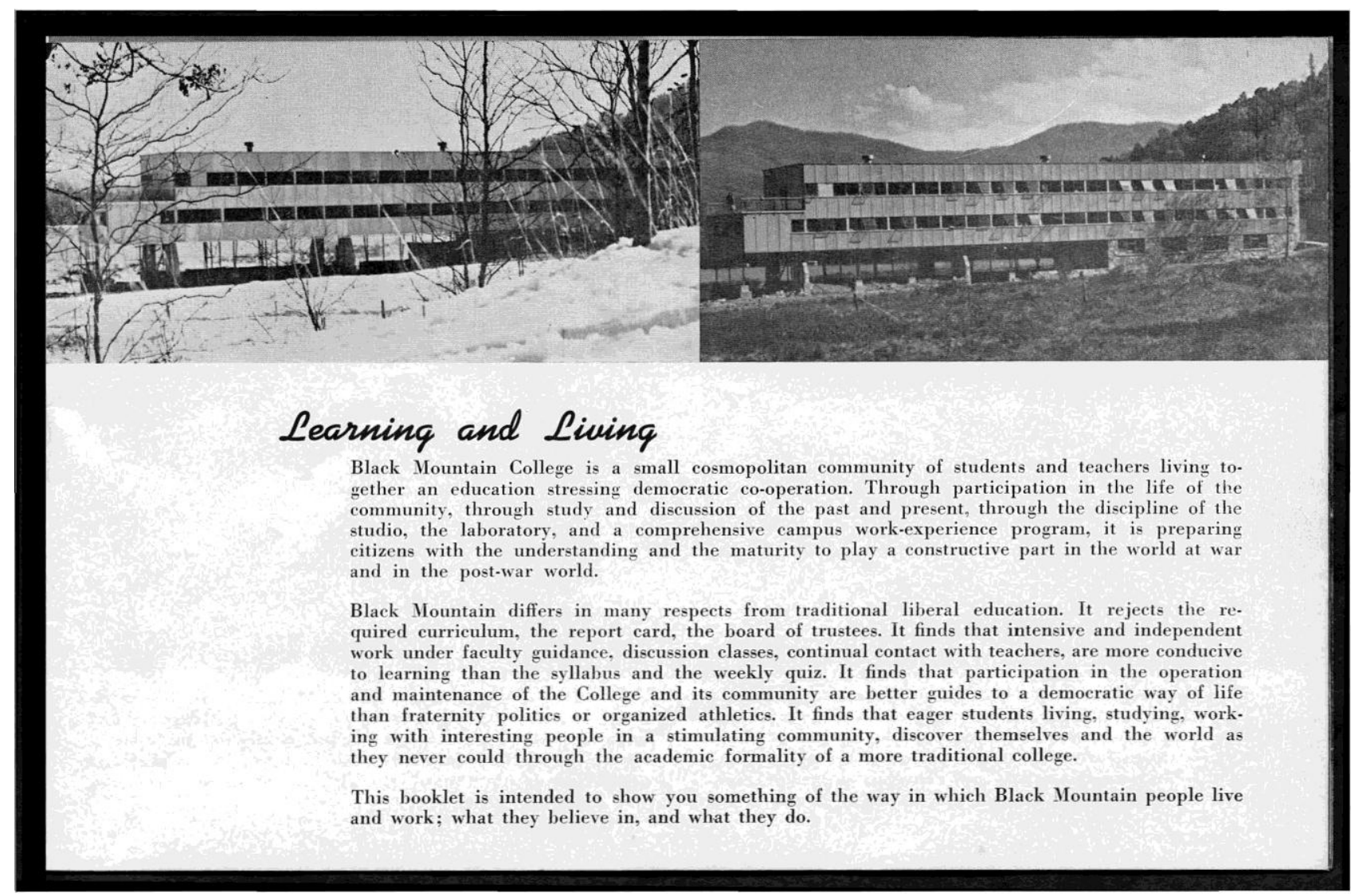

Fig. 01: Fragmento del boletín informativo del Black Mountain College, febrero de 1943. Black Mountain College Bulletin/ Bulletin-Newsletter, Vol. I, No. 3. February 1943.

\footnotetext{
${ }^{6}$ Josef Albers, 1929. KATZ, Vincent. (ed.). Black Mountain College: Una aventura Americana. Madrid: MNCARS (2002) p.10.

${ }^{7}$ Traducción de la frase original: "I want to open eyes", dicha por Josef Albers en la ceremonia de su incorporación al Black Mountain College y citada en la entrevista que M. Duberman realiza a Josef y Anni Albers en Noviembre de 1967.
}

DÍAZ, Emma. "Experiment, Expression and the Paradox of Black Mountain College". Starting at Zero: Black Mountain College 19331957. Cambridge: Bristol, Arnolfini with Kettle's Yard, Cambridge University, 2006. (en línea).( 8 de mayo de 2011).p.6. Disponible en: <www.engage.org/downloads/EvaDiaz.doc>.

La arquitectura como acontecimiento a través del Black Mountain College. Gilsanz Díaz, Ana.

DOI 10.14198/i2.2015.03.03 


\subsection{Acontecimientos arquitectónicos.}

Se ha realizado una selección de diversos acontecimientos que tuvieron lugar y que se entienden en el contexto y metodología docente del B.M.C. Se localizan temporalmente entre los años 1937 y 1952 y gran parte de ellos se desarrollan en la segunda localización del College en las instalaciones del Lago Eden ${ }^{8}$.

Los primeros acontecimientos van ligados a la figura de Xanti Schawinsky en la primera etapa del college, en el Campus de Blue Ridge Assembly, a través de dos representaciones donde los estudiantes son los protagonistas.

\section{"Spectodrama: Play, Life, Illusion".}

Dentro del curso "Estudios escénicos" de Xanti Schawinsky", en el que los estudiantes desempeñaban funciones de escenógrafos, músicos, actores, escritores u oradores, organiza dos representaciones escenográficas basadas en conceptos relacionados con la óptica a través de la mirada, la acústica, la arquitectura, la música y la ilusión.

La primera representación, en 1936, se fundamenta en la mirada y el oído con música improvisada de John Evarts $^{10}$. En ella participaron a parte del propio Schawinsky, Allan Sly ${ }^{11}$ y dos estudiantes: Beverly Coleman y George Hendrickson. La segunda tiene lugar en 1937 y se incorpora música de Kurt Schwitter, Basic Sound Sonata, y emplea la metodología heredera de Oskar Schlemmer de la Bauhaus.

Xanti Schawinsky ve el B.M.C como un laboratorio donde continuar sus experimentos iniciados en la Bauhaus. Estas producciones pueden considerarse el germen de lo que más tarde se denominó teatro performance. A diferencia de la improvisación que caracteriza los happenings, las representaciones están organizadas con una estructura narrativa planeada, donde la escenografía y los roles están perfectamente estructurados y jerarquizados. Se puede considerar un teatro experimental donde, concretamente en Spectodrama, muestra un método de intercambio entre las artes y las ciencias, empleando el color, la acción, el movimiento, la luz, el sonido, las palabras y los gestos, en la búsqueda de nuevas maneras de expresión y comunicación. Apuesta por el trabajo junto a otros profesionales de distintas disciplinas, para que las ideas y el conocimiento fluyan, diluyendo las fronteras que las separan.

\section{"The Danse Macabre : A sociological study".}

En 1938, en sus clases y al igual que en el caso anterior con los estudiantes, realiza esta representación que se desarrolla en el gimnasio. El origen es el texto medieval Dies Irae que es traducido por los estudiantes R. Sunley y M. Steneau.

Doce alumnos actores representan los personajes de la Danse Macabre, en un escenario central organizado mediante 3 círculos concéntricos de asientos. El público asistente llevaba capuchas negras y capas que les eran entregadas antes de la representación, de manera que fuesen rostros anónimos frente a la muerte. La iluminación mediante velas en círculo enfatizaba el efecto dramático. Incluyó una pieza musical compuesta por John Evarts, basada en variaciones improvisadas de Dies Irae.

Partiendo de una mirada hacia el pasado, las danzas macabras de la Edad Media, realizan una obra nueva donde se involucra al público, en este caso estudiantes, pero también vecinos de la zona y les hace partícipe de la acción. Puede considerarse una representación de la arquitectura de la acción que pretende generar una respuesta e interacción con el público y un antecedente del Untitled Event ${ }^{12}$ de 1952.

\footnotetext{
${ }^{8}$ El Black Mountain College tuvo dos emplazamientos, el Campus Blue Ridge Assembly,(1933-1940), alquilado en terrenos del Y.M.C.A y el Campus en el Lago Eden (1940-1957), adquirido en propiedad. Tras los intentos de compra del campus del Blue Ridge y los problemas con la propiedad, se vieron obligados a mudarse y buscar una nueva localización, fundando el Campus en el Lago Eden.

${ }^{9}$ Xanti Schawinsky fue profesor de arte, arquitectura y escenografía en el Black Mountain College desde 1936 hasta 1938.

${ }^{10}$ John Evarts impartió clases de música y estuvo vinculado al Black Mountain College desde su origen en 1933 hasta 1942.

${ }^{11}$ Allan Bernard Sly impartió música en el Black Mountain College desde 1935 hasta 1939.

${ }^{12}$ En agosto de 1952 en el comedor colectivo del B.M.C tuvo lugar el primer happening o performance multimedia, "Untitled event", organizado por John Cage y con una duración de 45min. En él participaron: John Cage, Robert Rauschenberg, David Tudor, Merce Cunningham, Richard Olson, M.C. Richards, alumnos y bailarines del Black Mountain. Muestra una participación múltiple en segmentos temporales que se van solapando sin estar relacionados una acción con otra. Aunque John Cage estableciese el límite temporal de cada participante, existían distintos momentos donde nadie podía prever el resultado de esas combinaciones. La acción se basaba en la relación e interacción de los agentes con el espectador, que se convierte en actor.
} 


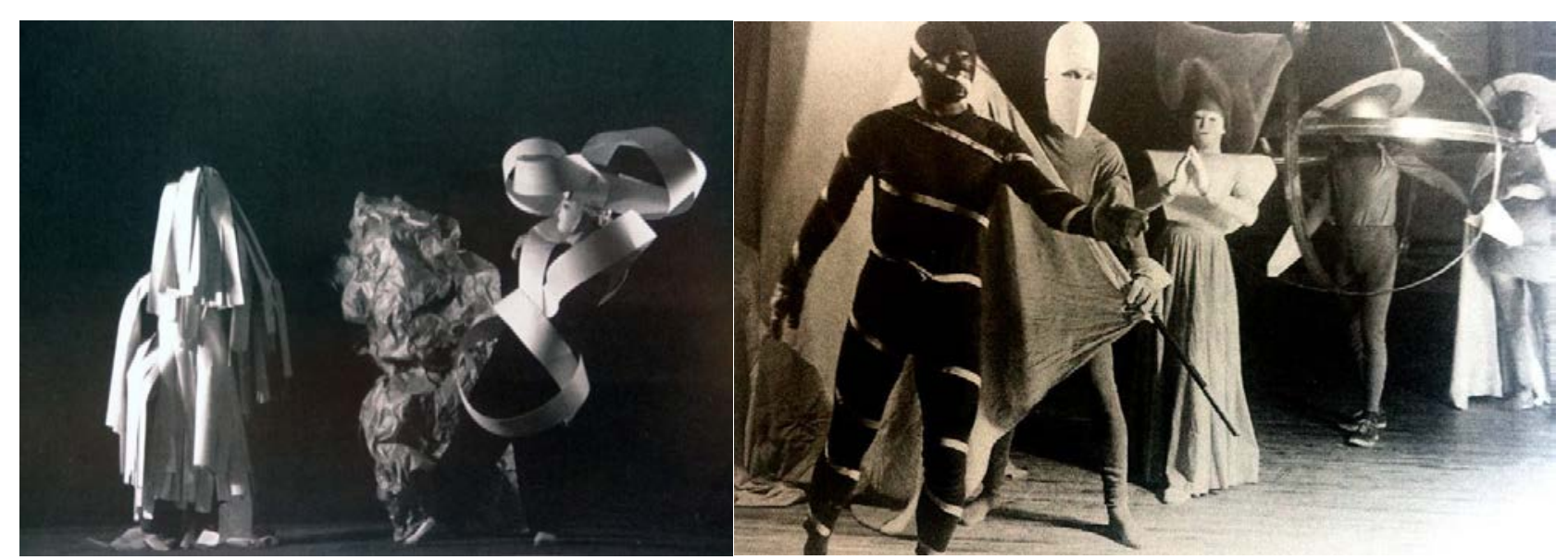

Fig.02: (Izq.) "pectodrama: Play, Life, Illusion. Parte IV, escena 1. Presentado en el Black Mountain College. (Drcha.) The Danse Macabre : A Sociological Study. Black Mountain College, sábado 14 de mayo de 1938.

\section{Programa de Arquitectura.}

El programa de arquitectura del College es en sí mismo un acontecimiento. Un programa integral organizado en proyectos y tareas de construcción colectivas, mezclando práctica y teoría. Los estudiantes se involucran en todas las fases del proceso mediante una participación activa, como mano de obra en la ejecución, en la dirección y en la viabilidad de los proyectos, mediante la organización de campañas de financiación para conseguir fondos para la construcción de nuevas edificaciones y adecuación de las existentes en el Campus del Lago Eden.

En estas acciones se muestra un interés por la construcción industrializada y el empleo de materiales baratos, en una búsqueda de optimización y abaratamiento de los recursos. Un concepto global de la arquitectura como actividad profesional social, que se ve reforzada por un gran número de visitas de profesionales del ámbito de la arquitectura y el diseño, que se acercaron a dar conferencias y a conocer el programa de arquitectura que tenía el B.M.C.

\section{Debate Arquitectónico.}

En febrero de 1946 el College encarga a T.A.C, The Architects Collaborative, grupo formado, en ese momento, por Walter Gropius con Norman y Jean Fletcher, Ben Thompson and John Harkness, el proyecto de una residencia para 40 mujeres en el B.M.C. Un encargo que pretendía atraer a alguno de los miembros del equipo para que se uniese al Black Mountain como arquitecto residente mientras durase el proyecto.

Jean Fletcher se establece en el College para estudiar el solar, determinar las necesidades del programa y discutir con los profesores y el alumnado las especificaciones del proyecto. De modo que se va modificando, prolongándose hasta verano cuando T.A.C hacen llegar la propuesta.

En paralelo, el estudiante Don Wight con otros compañeros realizan otra propuesta alternativa de pequeñas unidades habitacionales con zona de noche y estudio para seis estudiantes. Esta acción genera un debate interno de peticiones, revisiones y reuniones que cuestiona: "¿Cuando una decisión es una decisión en el Black Mountain College?". ${ }^{3}$

Resulta interesante cómo desde una iniciativa académica y partiendo de la propuesta de un alumno, se consigue generar un debate en materia de arquitectura sobre cómo se deben compaginar las actividades de vida y estudio en comunidad. Se realizaron diversas propuestas que fueron sometidas a debate y votación colectiva y, que se entienden en la convivencia democrática del B.M.C. Una iniciativa que recuerda a los procesos de participación ciudadana en la toma de decisiones relativas a la ciudad, al urbanismo y modos de habitar.

\footnotetext{
${ }^{13}$ Traducción del texto original. HARRIS, Mary Emma. The arts at Black Mountain College. Cambridge: The MIT Press, $2002\left(1^{\circ} \mathrm{ed}\right.$. 1987).p.114.
}

La arquitectura como acontecimiento a través del Black Mountain College. Gilsanz Díaz, Ana.

DOI 10.14198/i2.2015.03.03 


\section{“Minimum House".}

La implicación y receptividad del alumnado del College es una cualidad que genera resultados beneficiosos para la comunidad como es el caso de la Minimum House.

Ante la falta de un arquitecto coordinador en las clases, debido a que tras la guerra el programa de arquitectura pierde actividad, un grupo de estudiantes interesados en la arquitectura, formado por Ralph Chernoff, Bernard Karp, Albert Lanier, Alex Morse, Warren Outten, Sewell Sillman, Ragland Watkins y Paul Williams, deciden unirse para organizar un taller en el que proyectan una vivienda. La 'Casa Mínima', llevada a cabo entre el otoño de 1947 y verano de 1948, es una vivienda de bajo coste, para la que ellos realizan el diseño, la obra, el mobiliario y buscan los recursos para su materialización.

En cierta manera, funcionaron como un colectivo de los que actualmente se encuentran en activo, con una propuesta que deciden llevar a cabo, responsabilizándose del proceso completo. Una manera de trabajar autónoma, buscando sus propias estrategias para dar viabilidad al proyecto. Una propuesta que se entiende desde la acción como actitud vital en la comunidad del College.

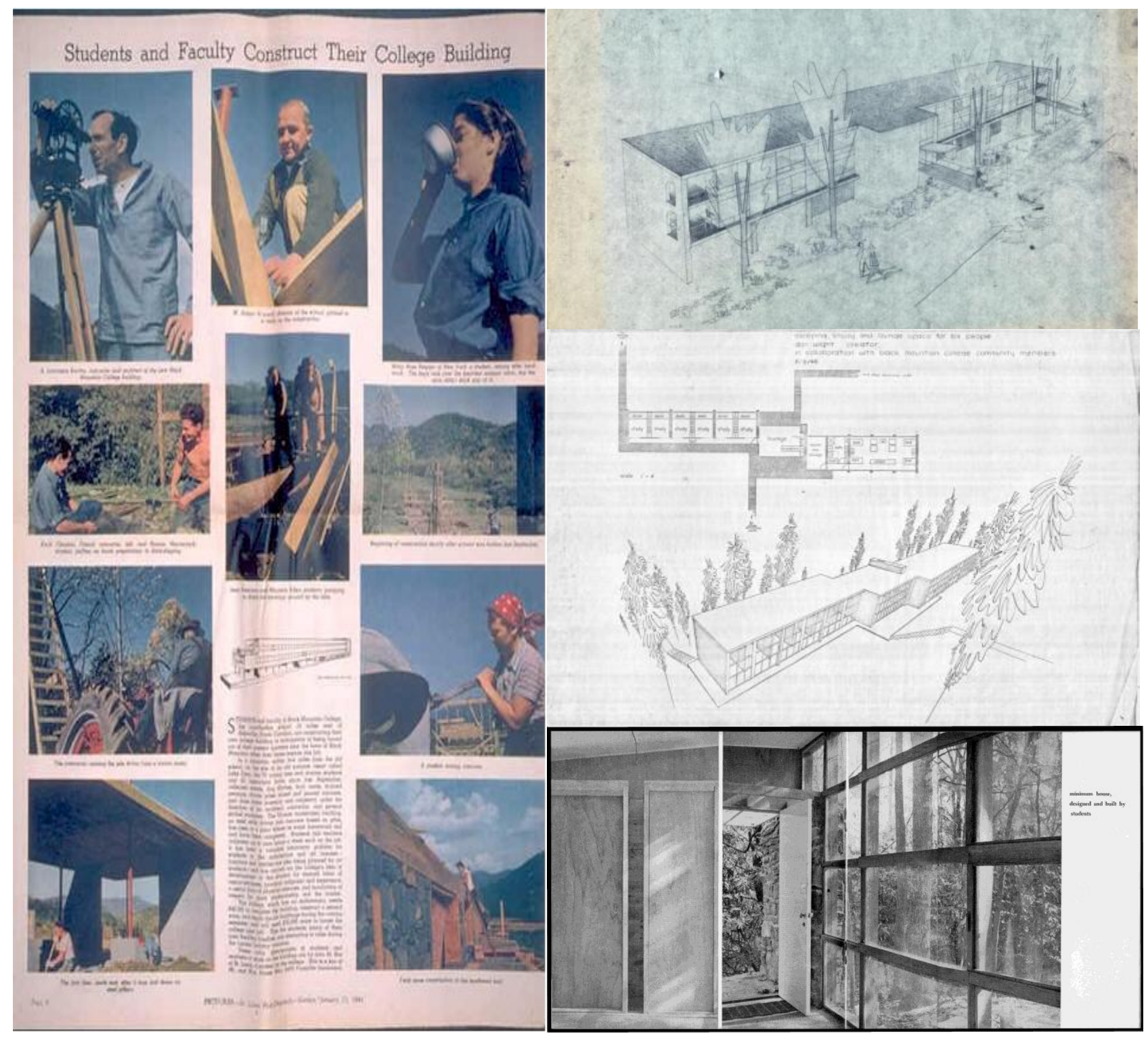

Fig.03: (Izq.) Artículo sobre la construcción del Edificio de Estudios publicado en St. Louis Post-Dispatch. Fotos realizadas por John Stix, estudiante del B. M.C. (Drcha.Sup) Propuesta de alojamientos para mujeres. The Architects Collaborative (TAC). Primavera de 1946. (Drcha. Central) Propuesta alternativa realizada por Don Wight en colaboración con los miembros de la comunidad del B.M.C. Junio de 1946. (Drcha.Inf.) Minimum House, proyectada y construida por los estudiantes. 
En los siguientes acontecimientos aparece la figura de Buckmisnter Fuller como protagonista, a través de tres eventos que tuvieron lugar en los dos veranos en los que impartió clase.

\section{"Supine Dome".}

En el verano de 1948, Buckminster Fuller con su interés por estructuras eficaces, que permitan lograr la máxima resistencia empleando el mínimo gasto y material, tiene por objetivo levantar su primera cúpula geodésica. Para ello cuenta con un equipo de trabajo formado por estudiantes y profesores: Si Sillman, Elaine De Kooning, Roger Lovelace, Josef Albers, Albert Lanier, Paul Williams, Willie Josep, Patt Passlof y Kenneth Snelson.

Se realiza con unas cintas de aluminio de lamas de persianas venecianas de unos $5 \mathrm{~cm}$, que formaban el esqueleto estructural, con el objetivo de levantar una cúpula hemisférica de aproximadamente $14.40 \mathrm{~m}$ de diámetro, en un área de $1.500 \mathrm{~m} 2$ y con un peso inferior a $122 \mathrm{~kg}$. Pero la estructura no funcionó y no se levantó. Buckminster Fuller era consciente de que existía un problema de dimensionado, pero por los medios de los que disponían únicamente pudieron adquirir los elementos de aluminio que emplearon.

Fue un proyecto que levantó el interés de toda la comunidad tanto por la presencia de Buckminster Fuller, como por la solución estructural que podría aplicarse en el College para resolver los problemas de escasez de alojamientos.

Este es un intento que realizan de manera colectiva, participativa y abierta a toda la comunidad del B.M.C. Se parte con un objetivo y se entiende como un proceso experimental donde el fracaso es parte del mismo. Tal y como Fuller dijo: "Alcanzas el éxito cuando dejamos de equivocarnos". ${ }^{14}$ Es necesario errar para conseguir el éxito y lo interesante es el acontecimiento de un proceso llevado a cabo como una acción colectiva sin tener relevancia el éxito o fracaso del resultado.

\section{"The Ruse of Medusa".}

Ese mismo verano, en la noche del 14 de agosto, se realiza una representación que forma parte de los 25 conciertos dentro del curso, "La defensa de Eric Satie", que organiza John Cage sobre la figura del músico. Este concretamente se fundamenta en la obra Le Piège de Méduse de 1913.

El texto original es traducido al inglés por M. C .Richards ${ }^{15}$ y en ella participan: John Cage ${ }^{16}$ como directororganizador al piano, Merce Cunningham ${ }^{17}$ como Jonás, el mono mecánico, Buckminster Fuller en el papel del Barón Medusa, Elaine De Kooning interpretando a Frisette, hija del Barón, Arthur Penn ${ }^{18}$ realiza la dirección de la obra, William De Kooning ${ }^{19}$ y Richard Lippold ${ }^{20}$ parte del vestuario y Clemens Kalischer las fotografías. El atrezzo y la escenografía es diseñada por Buckminster Fuller con los estudiantes: Ruth Asawa, Albert Lanier, Bruce Johns, Forrest Wright, Ray Johnson, Patt Passlof y Raymond Spillenger.

En esta representación se muestra la colaboración entre música, danza, teatro y artes visuales. Existe un guión sobre el que se desarrolla la acción, acompañado de siete piezas de danza creadas por Merce Cunningham de manera independiente a la composición musical de John Cage.

Representa una de las operaciones azarosas dirigida por John Cage, que se caracteriza por una estructura y música compuestas y pensadas por una parte, y una parte coreográfica montada al margen del discurso, que sin previo ensayo se representa de manera única. Se considera que marca el punto de arranque de exploraciones sobre conexiones azarosas entre acontecimientos en la producción artística. Por otro lado, resulta sugerente que no exista separación entre espacio de actuación y el público, provocando un efecto inesperado e irrepetible.

\footnotetext{
${ }^{14}$ Traducción del texto original. HARRIS, Mary Emma. ob.cit. p.151.

${ }^{15}$ Mary Caroline Richards impartió clases de literatura y teatro desde 1945 a 1951, con periodos de excedencia en los que temporalmente abandona el B.M.C.

${ }^{16}$ John Cage se une al B.M.C en los cursos de verano de 1948, 1952 y 1953.

${ }^{17}$ El bailarín y coreógrafo Merce Cunningham impartió clases en los cursos de verano de 1948, 1952 y 1953 . Fue precisamente en el B.M.C donde funda su propia compañía en 1953, MCDC ( Merce Cunningham Dance Company). En su origen estaba formada por los bailarines: Carolyn Brown, Viola Farber, Paul Taylor y Rey Charlip, y por los músicos John Cage y David Tudor.

${ }^{18}$ El director de cine Arthur Penn fue alumno del College pero también profesor ayudante de 1947 a1948.

${ }^{19}$ William de Kooning fue profesor de arte en ese mismo verano en el B.M.C.

${ }^{20}$ Richard Lippold impartió clases de escultura en uno de los talleres organizados ese mismo verano.
} 

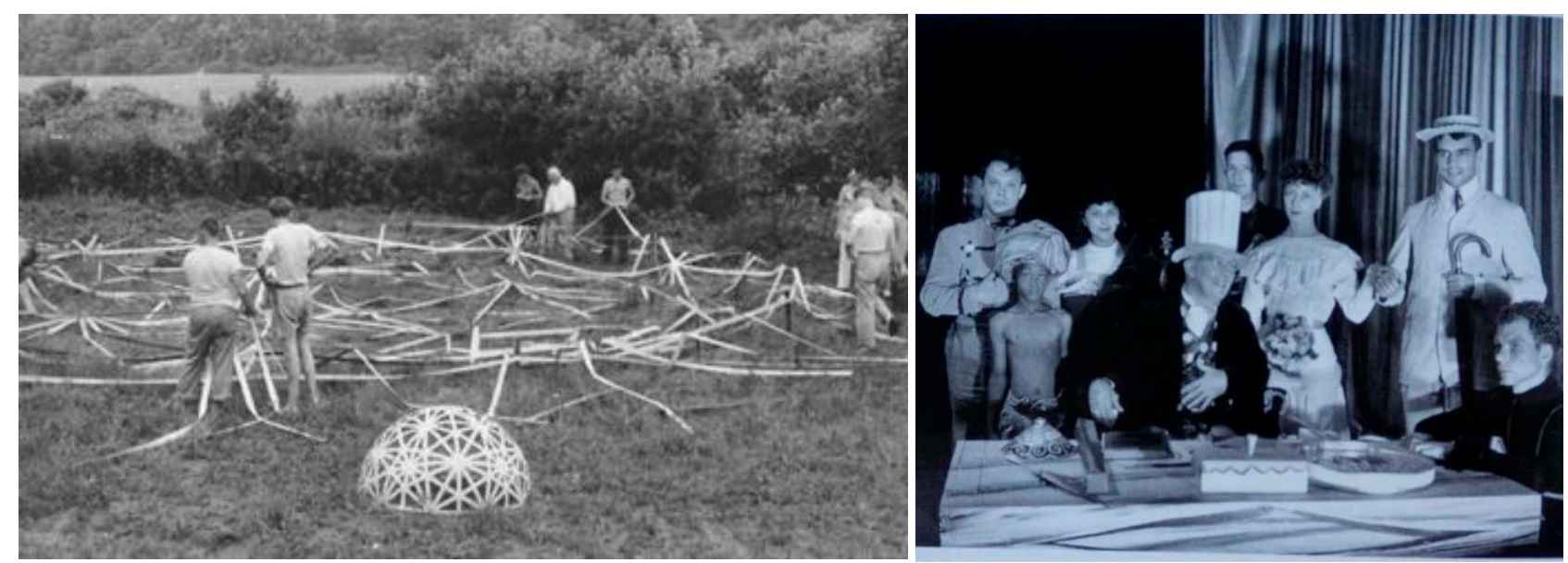

Fig.04: (Izq.) Supine Dome, verano 1948. Maqueta de la cúpula geodésica y preparación para levantar el modelo real. (Drcha.) Buckminster Fuller, John Cage, Elaine De Kooning, Merce Cunningham entre otros en The Ruse of Medusa (La Trampa de Medusa). 14 de agosto de 1948.

\section{"Geodesic Dome".}

En el verano de 1949, Buckminster Fuller vuelve a impartir clase en los cursos de verano acompañado de estudiantes del Institute of Design de Chicago, donde imparte clase. El grupo de estudiantes lo forman: Louis Caviani, Arthur Boericke, Eugene Godfrey, Mary Jo Slick Godfrey, Joseph Manulik, Alan Lindsay, Jeffrey Lindsay, Ysidore Martinez, Donald Richter, Robert Richter, Masato Nakagawa y Harold Young.

Tras el estudio durante el curso académico, de estructuras ligeras y la búsqueda de soluciones de vivienda industrializada, viene con el objetivo de realizar un nuevo prototipo de cúpula geodésica de escala más controlable y compuesta de elementos tubulares resistentes bien dimensionados. En febrero de ese año, en los jardines del Pentágono en Washington, había levantado una cúpula con la misma geometría que la del verano anterior, utilizando elementos tubulares más resistentes y reforzados con una red de cables. En este caso, vuelve a erigirla en el B.M.C, demostrando su resistencia y ligereza y dotándola de una envolvente plástica protectora.
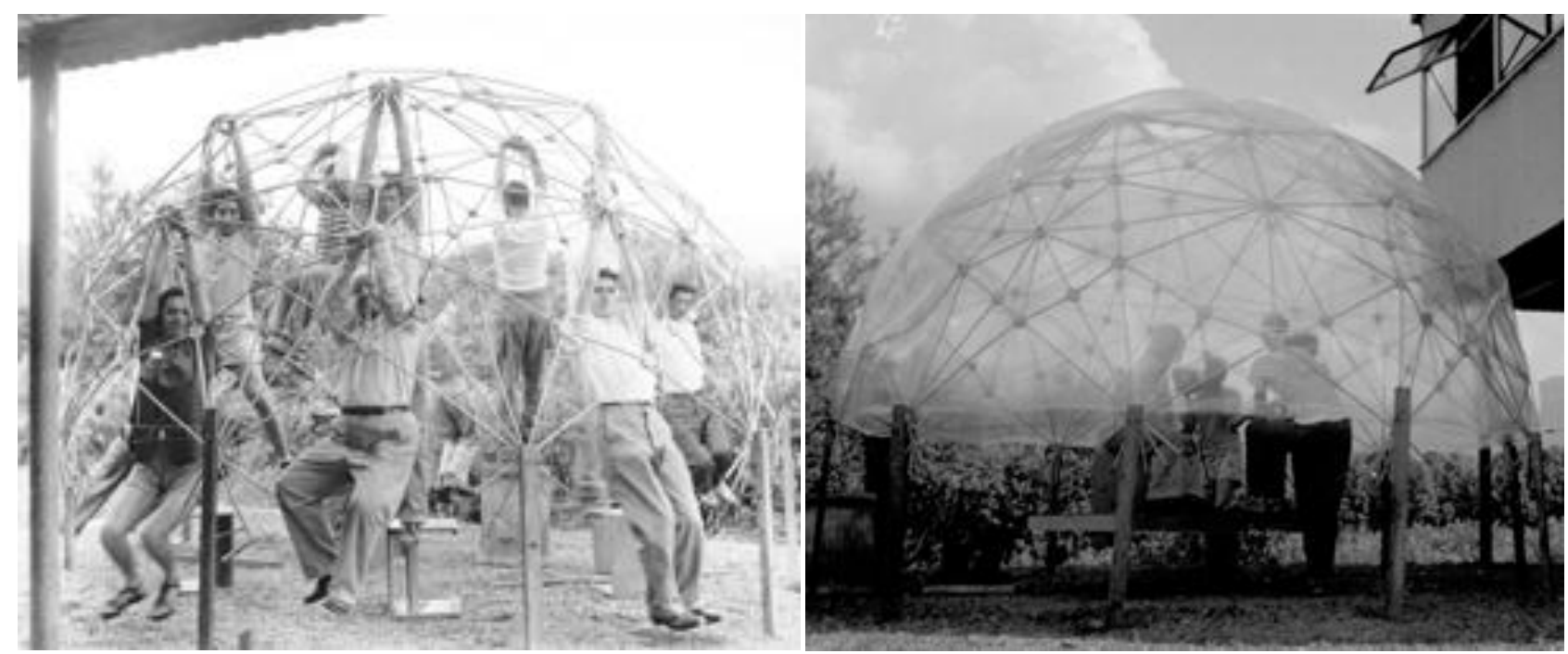

Fig.05: Prueba de resistencia de la cúpula geodésica. Geodesic Dome, verano de 1949. (Drcha.) Membrana protectora de la cúpula geodésica. Geodesic Dome, verano de 1949. 
Tras el primer intento fallido, el verano anterior, este segundo modelo, resultado de sus procesos investigativos, es válido, convirtiéndose en el germen del concepto de tensegridad ${ }^{21}$ que más adelante patentaría.

En este caso es muy claro como el B.M.C. fue un lugar para la experimentación desde una acción desarrollada en grupo convirtiéndose en acontecimiento. La concepción y éxito de la cúpula geodésica es una solución estructural con una repercusión en el contexto de la arquitectura, que a su vez, sirve de punto de arranque de diversas investigaciones en diversas disciplinas arquitectónicas y artísticas.

\section{La arquitectura en el Black Mountain College.}

En el B.M.C la presencia de la arquitectura es constante, con una actitud proyectual propositiva de planteamientos que en múltiples ocasiones llegan a materializarse y que forman parte, no sólo del curriculum formativo del College, sino también de la propia construcción del mismo. La arquitectura en este caso va directamente vinculada a la práctica, a la obra construida, de modo que entre todos fueron completando y adaptando el campus en función de las necesidades.

La arquitectura es entendida desde la formación dentro del contexto de las artes en el College, pero también como un proceso en el que la comunidad funciona como cliente en la toma de decisiones, adecuándose a la realidad, aplicando los conocimientos adquiridos y con un compromiso sobre sus acciones.

\subsection{Arquitectos del Black Mountain College.}

El B.M.C recibe un gran número de visitas de arquitectos o profesionales relacionados con la arquitectura de manera continuada a lo largo de su existencia. En los inicios aparece una menor presencia de la arquitectura hasta el año 1936 cuando Xanti Schawinsky, durante tres años, imparte clases de arte, arquitectura y escenografía, introduciendo en las mismas conceptos arquitectónicos y planteamientos relativos al espacio continuadores de la Bauhaus.

En estos años, en diciembre de 1937, realiza su primera visita Walter Gropius, desde Harvard donde se encontraba dando clase y coincidiendo con la compra de los nuevos terrenos junto al Lago Eden para la construcción de las nuevas instalaciones.

En el año 1938 el College recibe la visita de Marcel Breuer, examinador externo de los primeros graduados del B.M.C y socio de W. Gropius desde 1937 a 1941.También Lawrence Kocher ${ }^{22}$, figura destacada para entender el desarrollo y las propuestas arquitectónicas en la etapa central del College. Se reúne con Theodore Dreier ${ }^{23}$, para sugerirle que el edificio central de estudios del nuevo campus sea un proyecto realizado por los europeos Walter Gropius, Marcel Breuer, Josef Albers y Xanti Schawinsky. Finalmente, W. Gropius y M. Breuer realizan el proyecto que en el verano de 1939 es entregado al College. Un proyecto para unos 120 alumnos con un programa que albergaba aulas, talleres, dormitorios, complementados con una zona de reunión y salón comedor colectivo, así como por un teatro y una sala de música. Se realizaron varias campañas para su financiación, incluyendo la exposición en el MoMA del proyecto y la maqueta en enero de 1940, que resultan insuficientes para la viabilidad del mismo, por lo que acaba abandonándose.

Marcel Breuer visitó en varias ocasiones el College durante los años 1940 y 1941 para discutir el proyecto en la comunidad, impartir un curso en verano y a la vez supervisar las obras de la vivienda que diseñó para el Dr. Sprinza Weizenblatt en Asheville.

Por otra parte, la vinculación de Walter Gropius con el College se consolida en los cursos de verano de 1944

\footnotetext{
${ }^{21}$ El término original tensegrity, fue acuñado por Buckminster Fuller y es un principio estructural basado en el uso de componentes aislados comprimidos dentro de una red tensada continua de modo que sea una estructura auto equilibrada. El sistema se estabiliza mecánicamente a sí mismo, distribuyendo y equilibrando las fuerzas de tracción y compresión por el modo en que globalmente en su conjunto se distribuyen las tensiones. Se considera que el origen de este concepto nace en el B.M.C. de su encuentro con el alumno Kenneth Snelson, escultor que basó gran parte de su producción artística en este concepto.

${ }^{22}$ Lawrence Kocher fue profesor de historia de la arquitectura y diseño en la Universidad de Pennsylvania (1912-1926) y en la Universidad de Virginia (1926-1928), antes de convertirse en el editor de la revista Architectural Record desde 1928 hasta 1938. Junto con su socio Albert Frey es uno de los seis estudios de arquitectura norteamericanos que participan en la exposición: Modern Architecture, de 1932 sobre el Movimiento Moderno en el MoMA de Nueva York.

WODEHOUSE, Lawrence, "Kocher at Black Mountain". Journal of the Society of Architectural Historians. Vol.41 № 4. (1982) p.328-332.

${ }^{23}$ Theodore Dreier, ingeniero y profesor de matemáticas y física durante los años 1933 y 1949, fue rector entre 1946 hasta que abandona el College.
} 
cuando imparte el curso: "Site and Shelter after the War", en 1945: "Modern Architecture" y en sus estancias continuadas entre los años 1945 y 1946.
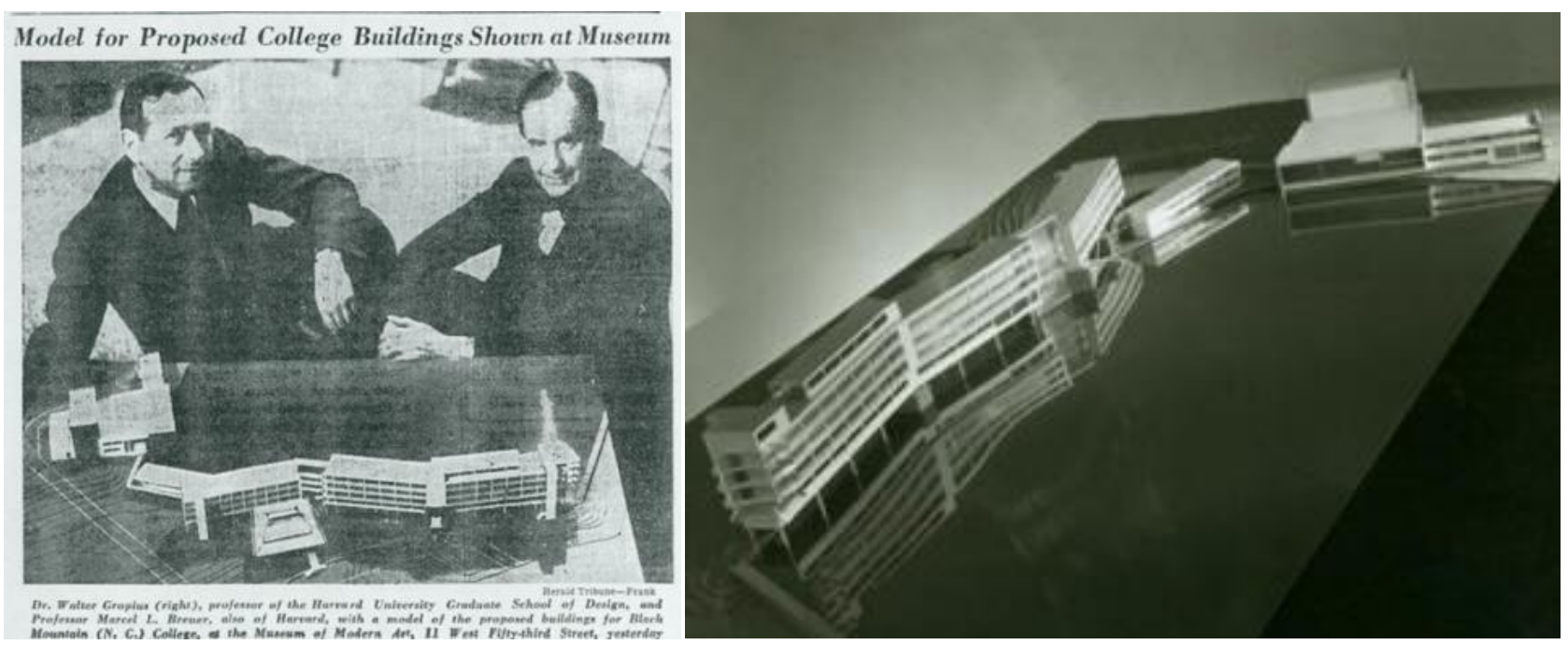

Fig.06: (Izq.) Marcel Breuer y Walter Gropius en el MoMA con la maqueta del proyecto. Publicado en el New York Herald Tribune, 10 enero 1940. (Drcha.) Maqueta del proyecto de Marcel Breuer y Walter Gropius para el campus del Lago Eden.

Durante el periodo comprendido entre los años 1940-46 se intensifica la presencia de arquitectos coincidiendo con el máximo desarrollo, en la existencia del B.M.C, de su programa formativo en arquitectura. Se manifiesta por un gran número de visitas y actividad arquitectónica apoyada por la presencia de arquitectos residentes como Lawrence Kocher, Horace McGuire Woods y de la diseñadora Molly Gregory.

Lawrence Kocher es uno de los arquitectos que se interesan e implican en el programa arquitectónico del College. Tras la inviabilidad del proyecto de W. Gropius y M. Breuer, en el verano de 1940 le encargan que realice un nuevo proyecto ${ }^{24}$ más simplificado y que pueda construirse en colaboración con el personal del College.

Durante la estancia de L. Kocher el programa docente que se centra en la arquitectura, representa el programa ideal que Gropius hubiese deseado en Harvard, puesto que combinaba clases teóricas y prácticas de construcción, apoyados con las clases de diseño y teoría del color impartidas por Josef Albers. Junto a Kocher, cuatro arquitectos colaboran impartiendo clases: Willo Von Molke ${ }^{25}$, Howard Dearstyne ${ }^{26}$, Antole Kopp ${ }^{27}$ y Lou Bernard Voigt $^{28}$.

En 1943 L. Kocher abandona el B.M.C marchándose a Nueva York a trabajar, cuando el número de estudiantes se había visto reducido considerablemente puesto que gran parte de ellos se habían ido a la guerra. A partir de su marcha el programa de arquitectura pierde intensidad.

Horace McGuire Woods ${ }^{29}$ entra como profesor de construcción y contable recogiendo en parte el testigo dejado tras la marcha de Kocher. Juega un papel clave en el momento crítico en el que se encuentra el College, llevan-

\footnotetext{
${ }^{24}$ Un proyecto inicial con un programa similar al que habían planteado Gropius y Breuer y que constaba de cuatro prismas longitudinales que nacían de un núcleo hexagonal. Finalmente se construye únicamente uno de los prismas que contiene las aulas y alojamientos. Una construcción de estructura metálica y de entramado de madera donde se muestra el interés por las construcciones ligeras y prefabricadas, que desarrollarán en diferentes proyectos en el Campus.

${ }^{25}$ Willo Von Molke, arquitecto berlinés que trabajó con A. Aalto y Xanti Schawinsky, entra como profesor en noviembre y diciembre de 1940. Tras su estancia en el B.M.C, se marcha a Harvard como docente y posteriormente es jefe de diseño urbano de Filadelfia.

${ }^{26}$ Howard Dearstyne, arquitecto americano graduado en la Bauhaus, colabora entre noviembre de 1941 y mayo de 1942 impartiendo clases de arquitectura y diseño de estructuras. Trabaja conjuntamente con Kocher en proyectos y también en la redacción y edición de libros.

${ }^{27}$ Antole Kopp imparte clases desde verano hasta octubre de 1942 y vuelve en la primavera de 1943, impartiendo lecciones de arquitectura, estructuras y escenografía.

${ }^{28}$ Lou Bernard Voigt es un arquitecto paisajista, que trabajará para S.O.M y que imparte clases de paisajismo y botánica entre el verano de 1942 y 1943.

${ }^{29}$ Horace McGuire Woods, llega en el verano de 1942 y prolonga su estancia hasta 1944, aunque durante el verano de 1943 y un semestre de 1944 se ausenta del College.
} 
do a cabo pequeñas construcciones, manteniendo las existentes y finalizando proyectos inacabados. Un arquitecto que muestra especial interés por la vivienda económica y la construcción ligera.

Cabe señalar la presencia mínima femenina en el ámbito de la arquitectura, reducida a la figura de Mary "Molly" Gregory ${ }^{30}$ como diseñadora de mobiliario y experta en trabajos de carpintería de madera que colaboró estrechamente con diversos arquitectos y se implicó activamente en la vida en el College.

En otra categoría destacaría la vinculación intensa de Buckminster Fuller, Paul Beidler y Paul Williams. Tres figuras con propuestas teóricas que llevan a la práctica en el College.

La llegada de Fuller al B.M.C para impartir sus cursos de verano es a través de la recomendación de Bertrand Goldberg $^{31}$. Los dos cursos de verano que imparte en años consecutivos, tal y como se ha comentado, resultan enriquecedores y sus propuestas se convierten en acontecimientos en el College con una gran repercusión.

Paul Beidler ${ }^{32}$ llega bajo recomendación de W. Gropius, para impartir clases de arquitectura e ingeniería. En su estancia en 1945, muestra interés por la vida y trabajo en comunidad, especialmente con propuestas arquitectónicas donde la arquitectura del College debe "reflejar la atmosfera de la investigación arriesgada para un nuevo y mejor entorno educativo y mostrar ese espíritu indagador que debe prevalecer si el Black Mountain quiere continuar siendo pionero en la educación del presente ${ }^{33}$. Realiza el proyecto del Music Cubicle, un aula de madera, hormigón y vidrio para la práctica con instrumentos en medio del bosque, que se construye en colaboración con los estudiantes.

Paul Williams representa uno de los ejemplos en los que el estudiante cambia de rol y se convierte en profesor, en este caso de arquitectura, vinculándose al College de 1947 hasta 1949 como alumno, en 1950 como profesor ayudante y en 1953 incorporándose al cuerpo docente como arquitecto residente. Su nexo con el B.M.C. abarca la financiación de gran parte de actividades por parte de él y de su familia que respalda económicamente el proyecto docente. Como alumno participa en el proyecto de la Minimum House y como arquitecto residente realiza el nuevo edificio de ciencias, que se había quemado en 1948, y el taller de cerámica The Pot Shop, en colaboración con Robert Turner ${ }^{34}$ en 1949-50.

En los años de 1948 a 1950 la actividad y presencia arquitectónica se ve mermada y queda concentrada en los cursos de verano y semestrales, perdiendo intensidad a partir de ese momento, hasta el cierre del B.M.C.

\subsection{Profesionales invitados.}

El B.M.C recibió visitas de profesionales de todas las áreas de conocimiento,como Carl Jung, Albert Einstein, Fernand Léger o Aldous Huxley, por citar a algunos. En el campo de la arquitectura las visitas son recurrentes y a la vez son una toma de contacto con lo que estaba pasando en el exterior. Tanto una apertura a los arquitectos europeos que llegan a Norte América como con profesionales en activo que desarrollan su carrera profesional en EE.UU.

Entre los europeos que se acercan al B.M.C están William Lescaze, Serge Chermaryeff, José Luis Sert, Bernard Rudofsky y Pierre Chareau.

Serge Chermaryeff, recién llegado de Europa, donde fue socio de E. Mendelsohn, es invitado en la primavera de 1940 al College. Se quedará en EE.UU. desarrollando la práctica privada y docente en el Instituto de Diseño de Chicago, Harvard, Yale y MIT.

En 1944 visitan el College José Luis Sert y Bernard Rudofsky. Este último es un arquitecto y diseñador austriaco que visita el College en el verano de 1944 para realizar un taller de diseño e historia de la moda y el calzado en colaboración con su mujer Berta. A la vez se encuentra organizando la exposición en el MoMA: Are our clothes

\footnotetext{
${ }^{30}$ Mary "Molly" Gregory entra como ayudante en las clases de Josef Albers en 1942 y prolonga su estancia hasta 1947. Imparte clases de diseño de mobiliario en madera y técnica de carpintería, compatibilizándolo con sus encargos privados y desde el año 1945 formó parte del comité del College, responsabilizándose de la gestión de la granja.

${ }^{31}$ Bertrand Goldberg, arquitecto de Chicago que asistió a la Bauhaus, visita el B.M.C en el verano de 1946 y realiza el proyecto de un edificio en homenaje a su mujer en el campus. Conoce a B. Fuller a través de su socio Leland Goldberg y le recomienda para que le sustituya en el curso de verano.

${ }^{32}$ Paul Beidler, arquitecto que trabajó con F. Lloyd Wright en Taliesin. Como arqueólogo trabaja en expediciones por Egipto, Irak e Italia de la Universidad de Pensilvania, donde se graduó. Trabaja con J. Duiker en Amsterdam y desarrolla su carrera como arquitecto en Honolulu, Los Ángeles, Nueva Jersey y Pensilvania.

${ }^{33}$ Traducción del texto original. HARRIS, Mary Emma. ob.cit. p.56.

${ }^{34}$ Alumno que trabaja de asistente en las clases de Paul Williams.
} 
Innovación e Investigación en Arquitectura y Territorio. Departamento de Expresión Gráfica y Cartografía. Arquitectura. Escuela Politécnica Superior. Universidad de Alicante. N³ septiembre 2015 ISSN: 2341-0515

modern?, que se expone entre noviembre de 1944 y marzo de 1945.

Pierre Chareau visita el College en septiembre de 1945, recomendado por artista Robert Motherwell, docente del College y con el que había coincidido en Paris. Imparte unas conferencias sobre la arquitectura y planificación de la posguerra.

Aparte reciben visitas relacionadas con Nueva York, a través de Philip Goodwin ${ }^{35}$ que es uno de los promotores de donaciones para el College y que lo visita en diciembre de 1940. Otra conexión con Nueva York y con el MoMA es a través de Edgar Kauffman $\mathrm{Jr}^{36}$, director del departamento de diseño industrial del museo y que imparte clases de diseño industrial en uno de los cursos de verano.

También se recibe a personal de otras universidades con las que mantienen contacto, como John Burchard ${ }^{37}$, Christopher Tunnard ${ }^{38}$, William Wurster, Catherine Bauer Wurster ${ }^{39}$ y Charles Burchard ${ }^{40}$.

\subsection{Los estudiantes.}

Más allá de un centro educativo, el B.M.C es un lugar donde la docencia se entiende en comunidad. Esta singularidad donde la convivencia es una cuestión cotidiana para lidiar con los problemas diarios, condiciona la actitud de los estudiantes. No sólo atienden a las clases y realizan sus tareas, sino que se implican en ellas de forma activa con una actitud comprometida y propositiva, como muestran los estudiantes que a continuación se señalan.

En primer lugar, enfatizar la presencia de cuatro estudiantes que durante o tras su permanencia en el College, se unen al profesorado impartiendo clases. Entre estos estaría Paul Williams del que ya se ha hablado.

Donald Page, alumno de Lawrence Kocher en 1940 ejerce de profesor ayudante. Como alumno resulta el ganador del concurso, convocado por John Burchard, entre estudiantes de arquitectura del MIT y del Black Mountain. Tras su estancia en el B.M.C y la guerra, asiste a Harvard donde se gradúa como arquitecto.

Alexander Reed es un estudiante vinculado desde los inicios, graduándose en arte en el B.M.C. Durante los años 1940-41 imparte clases de arte, durante la ausencia del matrimonio Albers que se toman un año sabático viajando a México y visitando Harvard. Vuelve a impartir clase en el verano de 1946. Muestra una relación intensa con el proyecto del B.M.C. que se plasma en iniciativas como el proyecto y la construcción de The Quiet House, lugar de meditación y encuentro de la comunidad, realizado con la colaboración Molly Gregory.

Dan Rice, alumno graduado en el B.M.C entre 1946-1953, representa claramente al estudiante activo que realiza una inmersión en la colaboración multidisciplinar. Durante sus años en el College participa en talleres artísticos como Light Sound Movement Workshop, realiza decorados, vestuarios y con una producción gráfica que incluye el diseño de algunas de las portadas de las publicaciones de Robert Creely. También prepara una plantación de tabaco con el objetivo de poder obtener una rentabilidad económica de la misma. En relación con la arquitectura, dirige la obra del edificio de ciencias, Science Building, junto con Stan Vanderbeek, autor del proyecto. En la última etapa del B.M.C en el año 1956, se une para impartir clases de arte.

Los estudiantes son aprendices del oficio de la construcción, puesto que son ellos la mano de obra que dispone el College para levantar sus edificios. Pero no sólo ejecutores, sino que adquieren responsabilidad dirigiendo y coordinando la obra. Las tareas físicas abarcan la construcción pero también el trabajo en los terrenos productivos del campus y el mantenimiento de la granja.

\footnotetext{
${ }^{35}$ Philip Goodwin junto con Edward Durrell Scott son los arquitectos autores del MOMA en 1939.

${ }^{36}$ Edgar Kauffmann Jr. es diseñador industrial que trabaja con F. Lloyd Wright en el proyecto de la casa de su familia "Edgar J. Kauffmann House", conocida como la Casa de la Cascada. Visita el B.M.C en dos ocasiones; en abril de 1941 y el verano de 1948.

${ }^{37}$ John Burchard es arquitecto y dirige por entonces el departamento de investigación sobre vivienda en MIT. Visita el B.M.C en tres ocasiones: Para impartir conferencias sobre la vivienda en 1941 y los problemas de la reconstrucción en Europa en 1945. Además organiza en 1942 un concurso entre alumnos del MIT y del B.M.C para el diseño de refugios anti bombas.

${ }^{38}$ Christopher Tunnard, arquitecto profesor de planeamiento y paisaje de la Universidad de Harvard ejerce de examinador externo para la graduación de alumnos del College en mayo de 1941.

${ }^{39}$ En abril de 1945 reciben la visita de William Wurster, decano de la Escuela de Arquitectura y Urbanismo en MIT y Catherine Bauer Wurster. El matrimonio de arquitectos imparte conferencias sobre arquitectura moderna y vivienda, respectivamente. Catherine Bauer Wurster, profesora en Harvard, centra su trabajo como arquitecta en la búsqueda y diseño de la vivienda social económica, participa en la política de vivienda estatal de 1937 siendo co-autora del libro U.S. Housing Act. En 1943 escribe el libro Modern Housing, libro de referencia en Norte América.

${ }^{40}$ Charles Burchard, profesor en Harvard que había visitado el College interesado en su programa de arquitectura, es invitado en el verano de 1948 e imparte un curso de arquitectura.
} 
Un modo de pensar que pone en práctica los conocimientos adquiridos, tal y como se anunciaba en la publicidad de 1943 para el curso para estudiantes de arquitectura e interesados en la construcción:

"EI ESTUDIANTE que recibe formación en arquitectura requiere de experiencia práctica en el campo de la construcción para complementar su formación de dibujo y teórica de las clases. La idea del trabajo de campo en los oficios de construcción es un corolario del concepto reflexivo de entender al arquitecto como 'constructor'. Se puede, probablemente, considerar como indispensable para el pleno desarrollo del estudiante. En este tiempo de guerra, esa experiencia ofrece oportunidades para el desarrollo del ingenio, del juicio práctico y de la capacidad para hacer frente a ciertos tipos de emergencia. Los estudiantes aprenden que los materiales tienen limitaciones y leyes propias y que trabajar con ellos requiere disciplina y técnica. Algunos estudiantes en el campo de trabajo alcanzan un alto grado de habilidad en los distintos tipos de tareas en los que se ven implicados; y para la mayoría de los estudiantes del conocimiento de primera mano con el pensamiento de la arquitectura moderna y los materiales es una valiosa la experiencia". ${ }^{41}$

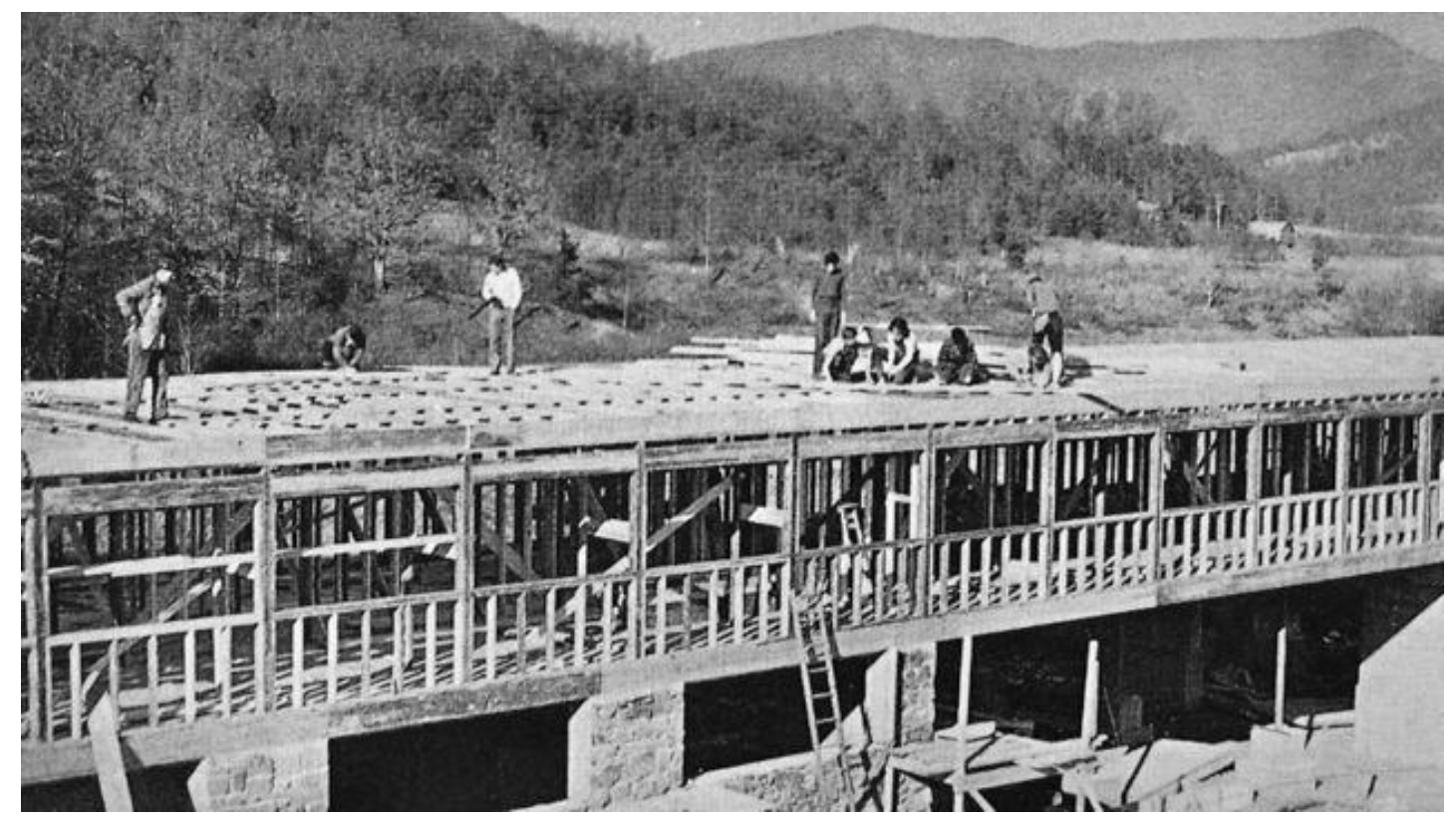

Fig.07: Estudiantes trabajando en el Edificio de Estudios en el Campus del Lago Eden, 1940.

\section{Aproximación a España en el Black Mountain College.}

A lo largo la existencia del College se detectan unas conexiones que se pueden establecer de manera directa con España y tangencial con nuestro idioma. Para ello, se han identificado esos vínculos organizándolos en función de la presencia de españoles en el College, la relación del B.M.C. con España y uso del idioma en la institución.

\subsection{Españoles en el Black Mountain College.}

Los vínculos se establecen principalmente a través de profesores que llegaron al B.M.C tras su marcha de España al finalizar la Guerra Civil.

En el verano de 1944 el arquitecto José Luis Sert es invitado a dar clase aunque él ya había estado en 1940, visitándolo junto con los arquitectos Philip Johnson y E. Durrel Scott. Desde su llegada a EE.UU. se dedica a la docencia, la práctica profesional ${ }^{42}$, la posibilidad de fundar un grupo CIAM norteamericano y a la redacción de su

\footnotetext{
${ }^{41}$ Traducción texto original. HARRIS, Mary Emma.Black Mountain College Project [en línea]. Disponible en web: <http://www.blackmountaincollegeproject.org/ARCHITECTURE/CURRICULUM/CURRICULUM.htm>.

${ }^{42}$ Sert fue profesor de arquitectura en la Universidad Yale y nombrado en 1953 decano de la Escuela de Diseño de la Universidad Harvard, La arquitectura como acontecimiento a través del Black Mountain College. Gilsanz Díaz, Ana.
}

DOI 10.14198/i2.2015.03.03 
texto sobre la ciudad funcional publicado en 1942: Can our cities survive? Entre los viajes que realiza entre los años 1943 y 1944 por las universidades norteamericanas como Harvard, Yale, Chicago, incluye una visita al B.M.C. ${ }^{43}$.

En el segundo semestre de 1944, ejerce como profesor de escultura José de Creeft ${ }^{44}$ que prolonga su estancia hasta finales del año, participando en la comunidad de manera activa a través de los cursos que imparte. Clases donde pone de manifiesto su modo de trabajar directamente la piedra y la madera, como materiales base de su trabajo y donde enseña a los estudiantes la autoconstrucción de las propias herramientas y la construcción de una forja.

El pintor español Esteban Vicente ${ }^{45}$, que visitó el College de manera intermitente a lo largo de los años 30, es invitado por Chales Olson ${ }^{46}$ en 1953 a impartir un curso en verano. Su presencia en el B.M.C se relaciona con la acción como medio de expresión en sus pinturas y la relación con otras disciplinas.

\subsection{Vínculos del Black Mountain College en España.}

Por otra parte, Irwin Lubroth, estudiante en el curso de verano de 1948, impartido por J. Albers, B. Fuller y C. Burchard, desarrolla su vida profesional en Madrid creando el estudio, aún en activo, Planifesa. Su estancia en el B.M.C se plantea desde la interdisciplinariedad, a través de las distintas clases que en parte determinaron su formación como arquitecto y fotógrafo profesional.

Robert Creely ${ }^{47}$, tras su estancia en Marsella, instala su residencia en Mallorca en 1953, concretamente en Bañalbufar y después en Bonova. Aquí coincide con otros poetas como Martin Seymour-Smith con quien colaborara en su proyecto editorial. Desde la imprenta Hermanos Mossen Alcover en Palma, es desde donde se imprimen las revistas ${ }^{48}$ del College, del que él es el editor, y los libros de su editorial Divers Press.

En otro apartado, cabe señalar la serie de pinturas realizadas por el artista Robert Motherwell ${ }^{49}$, representante del expresionismo abstracto norteamericano, que entre los años 1949 y 1976 realiza su serie "Elegías a la República Española".

\subsection{El idioma.}

El idioma estuvo presente a través de Lea Portell Vilá, mujer del historiador cubano Herminio Portell Vilá, que en el año 1937 impartió clases de español. El matrimonio se incorporó al B.M.C en el año 1935 y prolongaron su estancia hasta 1938, periodo durante el cual Herminio Portell Vilá fue profesor de historia. De origen cubano también era el escritor José Yglesias que fue alumno del College.

Por otro lado, el alumno Dan Rice que se involucró activamente en distintas actividades, impartió puntualmente clases de español a un grupo reducido de compañeros de manera informal.

cargo que ejerció hasta 1969. En EE.UU. crea junto Paul Lester Weiner, Paul Schulz e ingenieros como Elwyn E. Seelye el estudio de arquitectura y urbanismo Town Planning Associates.

ROVIRA, Josep M. (ed). Sert 1928-1979, Obra completa, Medio siglo de arquitectura. Barcelona: Fundació Joan Miró, (2005) p.111115.

${ }^{43}$ Estas visitas y conferencias son organizadas por Walter Gropius y Joseph Hundnut desde la Universidad de Harvard donde ejercían como docente y decano fundador, respectivamente.

${ }^{44}$ José de Creeft nace en Guadalajara en 1884 y muere en Nueva York en 1982, ciudad donde se instala desde su llegada a EE.UU. y donde desarrolla gran parte de su carrera profesional. Es amigo personal de José Luis Sert y con quien llega en verano al B.M.C.

${ }^{45}$ Esteban Vicente nace en Turégano, Segovia en 1903 y muere en Nueva York en 2001. Emigra a Estados Unidos en 1936, instalándose en Nueva York donde entabla amistad con los pintores representantes del expresionismo abstracto como Jackson Pollock, Marc Rothko, Barnett Newman, Willem De Kooning, y Franz Kline, estos dos últimos también profesores en el B.M.C. Su actividad artística la compatibiliza con la docencia en el B.M.C y en el New York Studio School of Drawing, Painting and Sculpture del que fue uno de sus fundadores.

${ }^{46}$ Charles Olson fue rector del B.M.C desde 1950 hasta el cierre en 1957.

${ }^{47}$ Robert Creely es profesor de literatura y escritura en B.M.C entre 1954 y 1957. Es el editor del Black Mountain Review, publicación del College que recogía los trabajos de alumnos y profesores.

${ }^{48}$ Se realizan 13 números del Black Mountain Review con tiradas de 500 a 700 ejemplares. Una vez impresos se las llevaba a EE.UU. en sus viajes de modo que le resultaba más económico que la impresión en los EE.UU. Estas publicaciones difundían los trabajos realizados en el College y con ellas se intentaba recaudar fondos para el desarrollo de actividades y el funcionamiento del College. Las publicaciones Black Mountain Review se relacionan directamente con la acción, entendiéndolas como modo de expresión y difusión de sus creaciones.

${ }^{49}$ Robert Motherwell fue profesor de pintura y crítica de arte en los cursos de verano de 1945 y 1951 en el B.M.C. 
El ingeniero Fernando Sáenz de León, de origen español, durante su estancia entre 1939 y 1941 en el B.M.C, imparte clases de español de manera complementaria a sus intereses vinculados a la construcción, donde es el encargado de la construcción de edificio de ciencias e involucrándose en la comunidad del College.

\section{Conclusiones y reflexiones.}

La arquitectura como acontecimiento tiene en el B.M.C una firme representación. A través de una concepción global de la profesión como una disciplina que abarca aspectos vitales determinantes en la definición de sus características, se anticipa a modelos más contemporáneos de producción arquitectónica, superando el determinismo moderno y aceptando un cierto grado de intervención del azar, la incertidumbre y el riesgo.

Sus aportaciones, más allá de un legado estrictamente material, son enseñanzas fundamentadas en una manera de entender el proceso creativo desde una actitud concreta e intencionada que toma como base la interacción entre los actores intervinientes (profesores y estudiantes) y los temas de trabajo libremente propuestos por cualquiera de los estamentos.

\section{Acontecimientos del Black Mountain College.}

Los acontecimientos estudiados, que tuvieron lugar en el B.M.C, fueron realizados por un colectivo o grupo de personas que formaban parte de la propia comunidad y del entorno artístico de EE.UU. Un grupo interdisciplinar que se reunía y coordinaba para llevar a la acción propuestas, y donde el resultado queda relegado a un segundo plano, puesto que el interés residía en el desarrollo de las mismas. Una parte de este colectivo procedía de Europa, muy vinculado con las enseñanzas de la Bauhaus (1919-33) y con el Movimiento Moderno de la arquitectura, por lo que, en parte, pueden considerarse continuadores de sus métodos de enseñanza, aprendizaje y proyectación, si bien evolucionaron introduciendo parámetros en la definición de la arquitectura como acontecimiento, dependiente de muchos factores e imposible de determinar a priori.

El proceso es entendido como una aventura sin certezas. Partiendo de hipótesis cuyos resultados podían ser imprevisibles, el azar aparecía como un elemento operativo. De alguna manera, asumían ciertos grados de riesgo procedentes de la imprevisibilidad de muchas de las propuestas que se llevaron a cabo. Colaboraciones basadas en la acción e interacción de los distintos agentes que participaban de las propuestas. Éstos se presentaban como oportunidades para conocer y explorar la realidad, una realidad que devenía múltiple y compleja, donde no bastaba con la previsión razonable mediante parámetros cuantificables objetivamente.

Los acontecimientos y sucesos están vinculados al contexto histórico, a la realidad del momento, donde surgen y se desarrollan, y a la comunidad del B.M.C que reunía las condiciones que invitaban a la experimentación. El College poseía una organización flexible y receptiva para admitir propuestas tanto por parte de profesores como de estudiantes.

La escala del B.M.C tanto por su localización como por su reducido número de estudiantes, se ve ampliada a un área de influencia internacional a través de la red de colaboradores de diversa procedencia geográfica y profesional que facilita la movilidad y la transferencia de información.

El B.M.C puede considerarse un hito singular, un 'laboratorio' de formación integral en torno a las artes. Un lugar de innovador potencial creativo, resultante del interés personal de sus participantes. Implicados con máxima intensidad en los distintos proyectos desarrollados. Éstos fueron el fruto palpable de la interacción entre los actores y sus disciplinas, siendo patente en los resultados obtenidos.

En él los proyectos se ajustaban a los medios disponibles y era el propio campus el que se adaptaba a las necesidades del momento, económicas y de personal, llegando incluso a sufrir distintas reconfiguraciones mediante la adecuación de sus instalaciones, la construcción de nuevas edificaciones y el aprovechamiento de los terrenos productivos.

\section{Arquitectura.}

El B.M.C apuesta por la formación en materia de arquitectura a lo largo de su existencia. A nivel formativo se presenta como una actividad global participativa que involucra al alumnado en todas las fases del proceso: proyecto, gestión, financiación, dirección y construcción.

El mero hecho de la construcción del continente arquitectónico mediante proyectos y construcciones que mejoren las instalaciones del campus, supone un primer posicionamiento claro al respecto de la que sería una de las disciplinas fundamentales de la institución. Una arquitectura participativa que a lo largo de su existencia adquiere un papel representativo y que nos habla de una actitud comprometida en términos sociales y económicos. 
Se pone la mirada en el presente para afrontar y proponer soluciones a los retos que surgen, huyendo de utopías con unos planteamientos que apuestan por la responsabilidad social del arquitecto. Hecho que se evidencia en su programa educativo, donde se fomentan actitudes creativas interactivas a través del análisis de la realidad. Una mirada que se compatibiliza con la revisión del pasado en algunos de los acontecimientos estudiados, reinterpretándolo a través de los resultados obtenidos mediante estas colaboraciones interdisciplinares. Como en el caso de la Danse Macabre de X. Schawinsky se rescata y reformula un texto del pasado, transformándolo en una representación influenciada por su paso por la Bauhaus, o en las propuestas de John Cage, donde se parte de la obra de Eric Satie, para crear composiciones inesperadas. Posicionamientos que, años después, han trascendido y siguen interesando, convirtiéndose en recursos para nuevas investigaciones.

\section{El Black Mountain College y España.}

Existen vínculos directos de la institución con España, conexiones a través de los profesionales españoles que se acercaron al B.M.C., contribuyendo a ensanchar su incipiente red colaborativa, y de los integrantes del mismo que se establecen en nuestro país continuando sus carreras. Este hecho nos hace más cercano un objeto de estudio que creíamos en un principio remoto, no solo por la distancia temporal.

\section{Enseñanzas del Black Mountain College.}

Los acontecimientos del B.M.C han sido un punto de partida de otras acciones e investigaciones y se han convertido en referentes. Acontecimientos que surgen de la voluntad y acción de los organizadores que hacen partícipe al usuario en la toma de decisiones, actitudes que se asemejan a los procesos de participación ciudadana.

La interdisciplinariedad se concibe desde el origen como parte del método docente y de aprendizaje, sin trabas ni limitaciones a priori. Hoy la arquitectura necesita la interconexión, el cruce de conocimientos y disolver las barreras entre disciplinas, para trabajar, enriquecer los procesos y ofrecer resultados satisfactorios.

Lo acontecido en esta institución se relaciona directamente con nuestra realidad donde los nuevos modos de trabajo tienen mucho que ver con los que se dieron allí. En un contexto actual donde las tecnologías lo han hecho especialmente accesible, proliferan colectivos multidisciplinares, redes de trabajo entre profesionales de diversas áreas, generando una diversificación en los modelos de creación colectiva de la que los arquitectos formamos parte. Unos modos de trabajo que se desarrollan gracias a internet como la red soporte para la acción y producción. Un funcionamiento de estructuras abiertas donde los componentes disfrutan de libertad para vincularse o no a los proyectos, tal y como sucedió en el College. Estructuras en muchos casos auto-organizadas, autogestionadas y auto-producidas, que nacen del interés y receptividad de los participantes. 


\section{Bibliografía.}

CHADDOCK REYNOLDS, Katherine. Visions and vanities : John Andrew Rice of Black Mountain College. Louisiana: Louisiana State University Press, 1998.

CHADDOCK REYNOLDS, Katherine. "The Influence of John Dewey on Experimental Colleges: The Black Mountain Example". Annual Meeting of the American Educational Research Association, San Francisco, 1995.

COLLIER, Caroline y HARRISON, Michael (eds).Starting at Zero, Black Mountain College 1933-1957. Bristol: Arnolfini, 2005. (en línea).( consultado 30 de abril de 2011). Disponible en: <http://www.ralphmag.org/ED/blackmountain.html>.

DAWSON, Fielding. The Black Mountain Book: A New Edition. North Carolina: North Carolina Wesleyan,1991.

DUBERMAN, Martin. Black Mountain: An exploration in community. New York: E.P. Dutton, 2009(1ªed. 1972).

DE SOLÁ MORALES, Ignasi. Diferencias: Topografía de la arquitectura contemporánea. Barcelona: Ed. Gustavo Gili, $2003\left(1^{\text {aed }}\right.$. 1995).

DEWEY, John. Art as an experience. New York: Perigee Books, 1980.

DÍAZ, Emma. "Experiment, Expression and the Paradox of Black Mountain College". Starting at Zero: Black Mountain College 1933-1957. Cambridge: Bristol, Arnolfini with Kettle's Yard, Cambridge University, 2006. (en línea).( 8 de mayo de 2011). Disponible en: <www.engage.org/downloads/EvaDiaz.doc>.

DÍAZ, Emma, Chance and Design: Experimentation in art at Black Mountain College. Princeton:Princeton University, 2009.

FOSTER, Norman y FERNÁNDEZ-GALIANO, Luis (eds). Buckminster Fuller 1895-1983. Madrid: Ed, Arquitectura Viva SL, 2010.

FÜSSL, Karl. "Pestalozzi in Dewey's Realm? Bauhaus Master Josef Albers among the German- speaking Emigrés' Colony at Black Mountain College (1933-1949)". Paedagogica Historica: International journal of the history of education. vol. 42, no. 1 (2006) pp. 77-92.

GAUSA, Manuel y DEVESA, Ricardo (eds.). Otra mirada: Posiciones contra crónicas. La acción crítica como reactivo en la arquitectura española reciente. Barcelona: Gustavo Gili, 2010.

HARRIS, Mary Emma. The arts at Black Mountain College. Cambridge: The MIT Press, $2002\left(1^{\circ} \mathrm{ed} .1987\right)$.

HARRIS, Mary Emma."The Continuing Relevance of Black Mountain College". The Chronicle of Higher Education, vol. 34, no. 29 (1988) pp. B3.

HARRIS, Mary Emma.Black Mountain College Project [en línea]. Disponible en web: $<$ http://www.blackmountaincollegeproject.org/>.

HAYS, Michael K. y MILLER, Dana. Buckminster Fuller. New York: Whitney Museum, 2008.

HOROWITZ, Frederick A. y DANILOWITZ. Brenda, Josef Albers: to open eyes: The Bauhaus, the Balck Mountain College and Yale. London: Phaidon, 2006.

KATZ, Vincent. (ed.). Black Mountain College: Una aventura Americana. Madrid: MNCARS, 2002.

KENTGENS- CRAIG, Margret (ed.). The Bauhaus and America: First contacts 1919-1936. Cambridge: The MIT Press, 1999.

MARTIN, Leslie. "Black Mountain College and Merce Cunningham in the Fifties: New Perspectives". Dance Research Journal vol.26 n¹ (1994) pp.46-48.

MUÑOZ JIMÉNEZ, María Teresa. "Verano de 1948. Buckminster Fuller en Black Mountain College. La Arquitectura como acontecimiento / Summer 1948. Buckminster Fuller at Black Mountain College. Architecture as an event". Proyecto, Progreso, Arquitectura no. 3 (2010) pp. 110-117.

ROVIRA, Josep M. (ed). Sert 1928-1979, Obra completa, Medio siglo de arquitectura. Barcelona: Fundació Joan Miró, 2005.

ROSENBERG, Harold. "The American Action Painters". Art News 51/8 New York (1952) p.22.

SCHAWINSKY, Xanti. "From the Bauhaus to Black Mountain". The Drama Review: TDR, vol. 15, no. 3. (1971) pp. 30-44.

STERN, Robert. A.M., MELLINS, Thomas, FISHMAN; David. New York 1960. Architecture and Urbanism between the Second World War and the Bicentennial. New York: Monacelli Press, 1995.

WICK, Rainer. Pedagogía de la Bauhaus. Madrid: Alianza Editorial, 2007 (1ºd 1982).

WODEHOUSE, Lawrence, "Kocher at Black Mountain". Journal of the Society of Architectural Historians. Vol.41 No 4. (1982) p.328-332.

La arquitectura como acontecimiento a través del Black Mountain College. Gilsanz Díaz, Ana.

DOI 10.14198/i2.2015.03.03 
WOLFE, Tom. La palabra pintada y ¿Quién teme al Bauhaus feroz?. Barcelona: Ed. Anagrama, 1981.

\section{Referencia de imágenes.}

Fig.01: AA.V, North Carolina State Archives, (4 de mayo de 2011). Disponible en: <http://digital.ncdcr.gov/cdm4/document.php?CISOROOT=/p249901coll44\&CISOPTR=617\&REC=2>

Fig.02: KATZ, Vincent (ed.). Black Mountain College: Una aventura Americana. Madrid: MNCARS, 2002. p.230.

Fig.03: (Izq.) STIX, John, Black Mountain College Project, (20 de mayo de 2014). Disponible en: <http://www.blackmountaincollegeproject.org/DOCUMENTS/st_louis_post-dispatch.htm>.

(Drcha. Sup.)HARRIS, Mary Emma, Black Mountain College Project, (25 de mayo de 2014). Disponible en: <http://blackmountaincollegeproject.org/ARCHITECTURE/CAMPUSES/LAKE\%20EDEN/UNREALIZED\%20PLANS/ ARCHITECTS\%20COLLABORATIVE\%20FLETCHER.htm>.

(Drcha.Central)HARRIS, Mary Emma, Black Mountain College Project, (25 de mayo de 2014). Disponible en: <http://blackmountaincollegeproject.org/ARCHITECTURE/CAMPUSES/LAKE\%20EDEN/UNREALIZED\%20PLANS/ ARCHITECTS\%20COLLABORATIVE\%20WIGHT.htm >.

(Drcha. Inf.)AA.WV, North Carolina State Archives, (3 de mayo de 2011). Disponible en: <http://digital.ncdcr.gov/cdm4/document.php?CISOROOT=/p249901coll44\&CISOPTR=636\&REC=1>.

Fig.04:(Izq.)NEWHALL,Beaumont, Black Mountain College Project, (2 de junio de 2014). Disponible en: <http://blackmountaincollegeproject.org/ARCHITECTURE/CAMPUSES/LAKE\%20EDEN/FULLER\%201948.htm>. (Drcha.) KATZ, Vincent (ed.). ob.cit. p.240.

Fig.05:NAKAGAWA, Masato, Black Mountain College Project, (2 de junio de 2014). Disponibles en: <http://blackmountaincollegeproject.org/ARCHITECTURE/CAMPUSES/LAKE\%20EDEN/FULLER\%201949.htm>.

Fig.06:(Izq.) HARRIS, Mary Emma, Black Mountain College Project, (2 de junio de 2014). Disponible en: $<$ http://blackmountaincollegeproject.org/ARCHITECTURE/CAMPUSES/LAKE\%20EDEN/UNREALIZED\%20PLANS/G ROPIUS\%20BREUER\%20MOMA\%20MEET.htm>.

(Drcha.)STOLLE, Ezra., Black Mountain College Project, (2 de junio de 2014). Disponible en: <http://blackmountaincollegeproject.org/ARCHITECTURE/CAMPUSES/LAKE\%20EDEN/GROPIUS\%20BREUER\%20 PLANS\%20images.htm>.

Fig. 07: AA.VV, Mondoblogo, (1 de marzo de 2011). Disponible en: <http://mondo-blogo.blogspot.com/2010/12/architecture-of-black-mountain-college.html>. 


\section{Biografía.}

\section{Ana Gilsanz Díaz.}

Arquitecta por la ETSAM, especialista universitaria en "Arquitecturas complejas para un mundo complejo" y Máster de Investigación en Arquitectura y Urbanismo sostenibles por la Universidad de Alicante (Premio extraordinario de máster universitario). Actualmente doctorando en la U.A.

He participado en talleres y conferencias en las universidades de Madrid y Alicante, colaborado en proyectos de investigación de la U.A. y elaborado con los profesores C. Barberá y J. Parra la publicación docente de la asignatura "Composición Arquitectónica 4" de la U.A.

He colaborado en y con varios estudios de arquitectura, enlazando arquitectura con disciplinas como el diseño gráfico, editorial e industrial, realizando la coordinación y diseño de varias publicaciones y, con obra y textos publicados en diversos medios. Compatibilizándolo con labor docente como colaboradora honorífica desde 2010 en el Área de Composición Arquitectónica, Departamento de Expresión Gráfica y Cartografía de la U.A.

\section{Ana Gilsanz Díaz.}

Architect by ETSAM, university specialist in "Complex architectures for a complex world" and Master in Architecture and Sustainable Urbanism at the University of Alicante (Extraordinary award in master's degree). Currently I am $\mathrm{PhD}$ candidate at the U.A.

I have participated in workshops and lectures at universities in Madrid and Alicante, collaborated in research projects of the U.A. and published with C. Barberá y J. Parra a book of the subject "Architectural Composition 4".

I have worked in and with various architectural offices, linking architecture with disciplines such as graphic, editorial and industrial design, coordinating and designing publications and published articles and projects in various media. Since 2010 I have been honorary fellow in the Department of Architectural Composition at the UA. 